\title{
Protective effect of porphyra-334 on UVA-induced photoaging in human skin fibroblasts
}

\author{
JINA RYU ${ }^{1}$, SU-JIN PARK ${ }^{1}$, IN-HYE KIM ${ }^{2}$, YOUN HEE CHOI ${ }^{2}$ and TAEK-JEONG NAM ${ }^{1,2}$ \\ ${ }^{1}$ Department of Food and Life Science, Pukyong National University, Busan 608-737; \\ ${ }^{2}$ Institute of Fisheries Sciences, Pukyong National University, Busan 619-911, Republic of Korea
}

Received February 7, 2014; Accepted June 11, 2014

DOI: $10.3892 / \mathrm{ijmm} .2014 .1815$

\begin{abstract}
The significant increase in life expectancy is closely related to the growing interest in the impact of aging on the function and appearance of the skin. Skin aging is influenced by several factors, and solar ultraviolet (UV) irradiation is considered one of the most important causes of skin photoaging. The aim of this study was to examine the anti-photoaging role of porphyra-334 from Porphyra (P.) yezoensis, a mycosporine-like amino acid (MAA), using highperformance liquid chromatography (HPLC), and electrospray ionization-mass spectrometry (ESI-MS). In the present study, extracted UV-absorbing compounds from $P$. yezoensis included palythine, asterina-330 and porphyra-334. Porphyra-334 was the most abundant MAA in $P$. yezoensis, and it was therefore used for conducting antiphotoaging experiments. The effect of porphyra-334 on the prevention of photoaging was investigated by measuring reactive oxygen species (ROS) production and matrix metalloproteinase (MMP) levels, as well as extracellular matrix (ECM) components and protein expression in UVA-irradiated human skin fibroblasts. Porphyra-334 suppressed ROS production and the expression of MMPs following UVA irradiation, while increasing levels of ECM components, such as procollagen, type I collagen, elastin. These results suggest that porphyra-334 has various applications in cosmetics and toiletries because of its anti-photoaging activities and may serve as a novel anti-aging agent.
\end{abstract}

\section{Introduction}

Intrinsic and extrinsic aging are two basic processes of skin aging. Extrinsic aging is generally referred to as photoaging and is characterized by severe wrinkling and pigmentary changes, such as solar lentigo and mottled pigmentation on exposed areas, such as the face, neck and forearms. Solar

Correspondence to: Professor Taek-Jeong Nam, Department of Food and Life Science, Pukyong National University, 5 Yongso-ro, Busan 608-737, Republic of Korea

E-mail:namtj@pknu.ac.kr

Key words: porphyra-334, UVA, anti-photoaging, human skin fibroblasts ultraviolet (UV) irradiation is a major environmental hazard that generates reactive oxygen species (ROS), induces DNA damage, and ultimately results in skin inflammation, photoaging, and cancer development (1).

Oxidative stress is considered a primary feature in aging and age-related diseases, including cataracts, atherosclerosis, diabetes and Alzheimer's disease. Aging is considered to be the consequence of free radical damage by various endogenous ROS, according to the original free radical theory of aging. ROS production and release can be affected by environmental factors such as UV radiation and exogenous toxins. Cytoprotective responses are characterized by the upregulation of antioxidant enzymes and decreased sensitivity to oxidative stress damage (2). Various compounds with differential antioxidant properties are found in plants, which may be applicable as therapeutics to decrease and prevent free radical damage. Several medical plants have been screened and assessed for properties in antagonizing free radical-induced oxidative stress, and their natural products are used to treat $87 \%$ of all classified human diseases $(3,4)$.

Recently, it was suggested that excessive matrix degradation by UV-induced matrix metalloproteinases (MMPs), which are secreted by various cells including keratinocytes, fibroblasts and inflammatory cells, contributes to connective tissue damage during photoaging (5-8). MMPs are a family of enzymes responsible for degrading connective tissue. They are structurally related endopeptidases that mediate the degradation of different macromolecular components of the extracellular matrix (ECM) and the basement membrane, including collagen. The UV-induced synthesis of MMPs present on dermal fibroblasts contributes to the breakdown of dermal interstitial collagen and other connective tissue components. These results are indicative of the MMP-mediated degradation of collagen in photodamaged skin. In particular, in photodamaged aging skin, increased ROS leads to the induction of AP-1 and $N F-\kappa B$ transcription factors, which consequently induce collagen degradation by the upregulation of MMPs. These properties make MMPs an attractive target for anti-photoaging compounds. ECM degrades naturally over time due to intrinsic aging. However, this breakdown is accelerated by external factors (especially UV irradiation) and the resultant oxidative stress, as well as increases in activity of MMPs.

Fibroblasts are the major cell component of the dermis that produces ECM proteins, as well as structural proteins 
(collagen and elastin), adhesive proteins (laminins and fibronectin), glycosaminoglycans (GAG) and proteoglycans. The most abundant structural protein in skin connective tissue is type I collagen (90\% of ECM in dermis), which is synthesized primarily by fibroblasts and is responsible for conferring strength and resilience to cells (9). Elastin is an essential part of various human tissues that depend on elasticity, including the skin, lung and arteries. Elastin provides these elastic tissues with the ability to stretch and recoil, and it plays a critical role in supporting and maintaining healthy cells (10).

Mycosporine-like amino acids (MAAs) possess significant chemoprotective effects against photo-induced skin senescence (11). MAAs found in and isolated from a number of marine organisms, such as cyanobacteria, algae, and heterotrophic bacteria, have attracted a great deal of interest, especially for potential UV protection. In a recent study, it was suggested that MAAs have antioxidant properties and UV absorbance activity (12). An important MAA is porphyra-334, which has been reported to act mainly in photoprotection, but it also posseses antioxidation abilities. Results of a recent study have shown that algae extracts prevent UV-induced photodamage in human keratinocytes (13). Although the photo-protective effect of MAAs in algae and tissue has been reported $(14,15)$, little is known regarding its effects on the aging process of skin cells. This study investigated whether supplementation with porphyra-334, an active MAA from Porphyra (P.) yezoensis, inhibits UVA-induced cellular senescence in human skin fibroblasts.

\section{Materials and methods}

Extraction and isolation of water-soluble porphyra-334. The porphyra-334 extraction method was performed as previously described (16) with minor modifications. Briefly, dried $P$. yezoensis $(100 \mathrm{~g})$ was ground and extracted in hydrophilic solvent consisting of $80 \%$ aqueous methanol (v/v) at $45^{\circ} \mathrm{C}$ for $2 \mathrm{~h}$. The extract was filtered (no. 3, $90 \mathrm{~mm}$; Advantec, Tokyo, Japan) to remove powder particles, and the residual aqueous suspension was evaporated to dryness under vacuum at $41^{\circ} \mathrm{C}$ (EYELA N-1100; Tokyo Rikakikai Co., Ltd., Nihonbashi Honcho, Japan). The dried extract was dissolved in $150 \mathrm{ml}$ ultrapure water and transferred to a separating funnel containing $666 \mathrm{ml}$ chloroform-methanol-ultrapure water $(2: 1: 1, \mathrm{v} / \mathrm{v} / \mathrm{v})$. The upper layer containing crude MAAs was collected. The water layer was then filtered through $0.2-\mu \mathrm{m}$ pore-sized syringe filters (Woongki Science, Seoul, Korea) and loaded onto a Strata C18-E cartridge (Phenomenex, Inc., Torrance, CA, USA) (previously equilibrated with ultrapure water) for analysis.

High-performance liquid chromatography (HPLC) analysis. Porphyra-334 was purified using an Agilent 1100 series HPLC system equipped with a diode array detector (DAD; Agilent Technologies, Inc., Palo Alto, CA, USA). The HPLC conditions used were: column, Gemini-NX $5 \mu \mathrm{C} 18$ (i.d. 250x21.20 mm; Phenomenex); column temperature, RT; flow rate, $30 \mathrm{ml} / \mathrm{min}$; mobile phase, $0.1 \%$ acetic acid in $\mathrm{H}_{2} \mathrm{O}$; and wavelength for detection, $334 \mathrm{~nm}$. Purified porphyra-334 was stored in the dark at $-70^{\circ} \mathrm{C}$ until analysis. Identification of MAAs was performed using UV absorption spectra and mass spectrometry.
Electrospray ionization-mass spectrometry (ESI-MS) analysis. To identify the peaks of fingerprints, the Agilent 1100 series (Agilent Technologies) ion-trap mass spectrometer with an electrospray ionization (ESI) source was used for the HPLC/MS method. ESI-MS conditions of each HPLC peak were set as follows: scan mass range, $\mathrm{m} / \mathrm{z}$ 100-600; fragmentor voltage, $70 \mathrm{~V}$; drying gas $\mathrm{N}_{2}$ flow rate, $12 \mathrm{l} / \mathrm{min}$; sheath gas flow rate, 60 arbitrary units; drying gas temperature, $350{ }^{\circ} \mathrm{C}$; and capillary voltage, $3,000 \mathrm{~V}$.

Cell culture. Human skin fibroblasts (CCD-986sk) were obtained from the American Type Culture Collection (ATCC, Manassas, VA, USA). Cells were grown in Dulbecco's modified Eagle's medium (DMEM; Gibco, Grand Island, NY, USA) containing $10 \%$ (v/v) fetal bovine serum (FBS; HyClone, Logan, UT, USA) and 1\% (v/v) penicillin-streptomycin (Gibco) under a humidified atmosphere of $5 \% \mathrm{CO}_{2}$ at $37^{\circ} \mathrm{C}$.

UVA irradiation and treatment. Prior to UV irradiation, cells were washed with PBS and exposed to a radiation dose of $10 \mathrm{~J} / \mathrm{cm}^{2}$ of UVA light (BLX-254; Vilber Lourmat, Marne La Vallee, France) in PBS. Subsequent to irradiation, the treated cells were washed with PBS and replaced with different concentrations of porphyra-334 for $24 \mathrm{~h}$. Concomitantly, no irradiation control cells were treated in the same manner, although the wells were covered with aluminum foil to prevent irradiation.

Cell viability. Cell viability was determined using a 3-(4,5-dimethylthiazol-2-yl)-5-(3-carboxymethoxy-phenyl)-2(4-sulfophenyl)-2H-tetrazolium (MTS) assay (Promega Corp., Madison, WI, USA) according to the manufacturer's instructions. Briefly, $2 \times 10^{4}$ cells/well were plated and allowed to attach to 96 -well plates. The cells were then exposed to serial concentrations of porphyra-334 for $24 \mathrm{~h}$. After $24 \mathrm{~h}$, a soluble MTS reagent was added and absorbance of the formazan was measured directly in 96-well plates at $490 \mathrm{~nm}$ using a multiplate reader (SpectraMAX 340PC; Molecular Devices, Sunnyvale, CA, USA). Relative cell viability was calculated as the percent viability relative to the untreated control cells. Each experiment was performed in triplicate.

Senescence-associated $\beta$-galactosidase (SA- $\beta$-gal) staining. SA- $\beta$-gal activity was determined at $24 \mathrm{~h}$ after UVA irradiation. A cellular senescence assay kit (Cell Biolabs, Inc., San Diego, CA, USA) was performed according to the manufacturer's instructions. Briefly, the cells were washed twice in PBS and incubated at room temperature for $5 \mathrm{~min}$ with fixing solution. The cells were washed three times with PBS, the final wash was aspirated, and the cells were completely covered with freshly prepared cell staining working solution. The cells were then incubated in the dark overnight at $37^{\circ} \mathrm{C}$. Following removal of the cell staining solution, the cells were washed twice with PBS and blue-stained senescence cells were observed using a light microscope (Olympus Microscope System IX51; Olympus, Tokyo, Japan).

Intracellular ROS production. The production of intracellular ROS was measured using the redox-sensitive fluorescent dye 2'-7'-dichlorofluorescein diacetate [DCF-DA $\left(\mathrm{C}_{24} \mathrm{H}_{14} \mathrm{C}_{12} \mathrm{O}_{7}\right)$; Sigma-Aldrich, Inc., St. Louis, MO, USA]. The ability of cells 
to produce ROS was measured by fluorescence. The cells were treated with $25 \mu \mathrm{M}$ DCF-DA for $30 \mathrm{~min}$ at $37^{\circ} \mathrm{C}$ and washed twice in PBS. Representative images were obtained using a fluorescence microscope (Olympus Microscope System IX51; Olympus).

Elastase activity. Elastase activity using the synthetic substrate N-Succinyl-Ala-Ala-Ala-p-nitroanilide (STANA; Sigma-Aldrich) was measured as previously described (17). Briefly, $100 \mu \mathrm{l}$ of enzyme solution was dispensed into 96-well plates, which were pre-incubated for $15 \mathrm{~min}$ at $37^{\circ} \mathrm{C}$. Following the addition of $2 \mu 155.3 \mathrm{mM}$ STANA, the plates were further incubated for $1 \mathrm{~h}$ at $37^{\circ} \mathrm{C}$. The release of p-nitroaniline was measured by absorbance at $410 \mathrm{~nm}$ and enzymatic activity was expressed as a percentage of total p-nitroaniline.

Total collagen. Total collagen synthesis in fibroblasts was measured using the Procollagen Type I C-Peptide (PIP) EIA kit (Takara Bio Inc., Otsu, Japan) according to the manufacturer's instructions. Briefly, $100 \mu \mathrm{l}$ of antibody-POD conjugate solution were added to appropriate wells, after which $20 \mu \mathrm{l}$ of cell culture medium was added to the wells within 5 min and incubated for $3 \mathrm{~h}$ at $37^{\circ} \mathrm{C}$. The contents were removed by suction and the wells were washed four times with $300 \mu \mathrm{l}$ of washing buffer. Substrate solution $(100 \mu \mathrm{l})$ was added to each well and incubated at room temperature for $15 \mathrm{~min}$. Subsequently, $100 \mu \mathrm{l}$ of stop solution was added to all the wells, and absorbance was read at $450 \mathrm{~nm}$.

Reverse transcription-polymerase chain reaction (RT-PCR). Total RNA from each sample was extracted using TRIzol reagent (Invitrogen, Carlsbad, CA, USA). According to the manufacturer's instructions, total RNA $(1 \mu \mathrm{g})$ was subjected to first strand cDNA synthesis using a Reverse Transcriptase PreMix kit (Intron Biotechnology, Inc., Gyeonggi-do, Korea). PCR amplification of the cDNA products was performed with $2 \mathrm{X}$ TOPsimple ${ }^{\mathrm{TM}}$ DyeMIX(aliquot)- $n$ Taq (Enzynomics, Daejeon, Korea) and primer pairs. Amplified products were separated by $1 \%$ agarose gel electrophoresis and visualized with $1 \mathrm{mg} / \mathrm{ml}$ ethidium bromide. mRNA levels were normalized using GAPDH as an internal control.

Western blot analysis. After treatment, cells were washed twice with PBS, harvested and lysed in RIPA buffer [50 mM Tris (pH 7.4), $1 \mathrm{mM}$ ethylene glycol tetraacetic acid (EGTA), $150 \mathrm{mM} \mathrm{NaCl}, 1 \%$ Triton $\mathrm{X}-100,0.25 \%$ sodium deoxycholate] containing protease inhibitor cocktail (Geno Technology, Inc., St. Louis, MO, USA). The lysates were centrifuged at $13,475 \mathrm{x}$ g for $15 \mathrm{~min}$ at $4^{\circ} \mathrm{C}$ (Smart-R17; Hanil Science Industrial, Incheon, Korea). Supernatants were collected and their protein concentrations were determined using a BCA protein assay kit (Pierce Biotechnology, Inc., Rockford, IL, USA). Equal amounts of protein $(30 \mu \mathrm{g})$ were boiled for $10 \mathrm{~min}$ and separated using 7.5-15\% sodium dodecyl sulfate-polyacrylamide gel electrophoresis (SDS-PAGE). The resolved proteins were then transferred to polyvinylidene difluoride (PVDF) membranes (Millipore Corp., Billerica, MA, USA). The membranes were blocked by incubation with $1 \%$ bovine serum albumin (BSA) in TBS-T $[10 \mathrm{mM}$ Tris- $\mathrm{HCl}, 150 \mathrm{mM} \mathrm{NaCl}$ (pH 7.5) containing 0.1\% Tween-20] at room temperature for $1 \mathrm{~h}$ and incubated with specific primary antibody (Santa Cruz Biotechnology, Inc., Santa Cruz, CA, USA) for $3 \mathrm{~h}$. The membranes were washed three times with TBS-T and incubated for $2 \mathrm{~h}$ with the appropriate HRP-conjugated goat anti-rabbit, goat anti-mouse or rabbit anti-goat secondary antibody (Santa Cruz Biotechnology) diluted at 1:10,000 in TBS-T containing 1\% BSA. The respective proteins were detected with SuperSignal ${ }^{\circledR}$ West Pico (Thermo Fisher Scientific, Inc., Rockford, IL, USA). Equal protein loading was assessed by the detection of GAPDH levels.

Statistical analysis. The results were presented as means \pm SEM from at least three independent experiments. Data were analyzed using one-way analysis of variance (ANOVA) with the Student's t-test using SPSS 10.0 (SPSS, Inc., Chicago, IL, USA). Differences were considered significant at $\mathrm{p}<0.05$.

\section{Results}

Identification of MAAs. As shown in Fig. 1A, the HPLC analysis of $P$. yezoensis revealed various absorption peaks at $334 \mathrm{~nm}$. Peaks were identified tentatively by comparing retention times with known standards (peak 1, 2.29 min; peak 2, $2.493 \mathrm{~min}$; and peak 3, $11.53 \mathrm{~min}$ ). We then identified the three peaks using LC/MS analysis. Peak 1, 2 and 3 showed $[\mathrm{M}+\mathrm{H}]^{+}$ ions at $\mathrm{m} / \mathrm{z}, 245.1,289.1$ and 347.1. Peak 1 was tentatively identified as palythine, peak 2 as asterina-330 and peak 3 as porphyra-334. Porphyra-334 was the most abundant MAA in P. yezoensis. Therefore, the following photoaging protection experiments were conducted using porphyra-334.

Effect of porphyra-334 on cell viability. To determine the cytotoxic effect of porphyra-334 on human skin fibroblasts, cell viability was measured using the MTS assay. Human skin fibroblasts were incubated with or without porphyra-334 at concentrations of $0-200 \mu \mathrm{M}$. As shown in Fig. $2 \mathrm{~A}$, no significant toxicity was observed in the cells treated with porphyra-334 for $24 \mathrm{~h}$. To explore the protective effect of porphyra-334 on UVA-induced cell damage, human skin fibroblasts (previously exposed to UVA irradiation) were incubated with various concentrations of porphyra-334 (0-40 $\mu \mathrm{M})$. As shown in Fig. 2B, treatment with porphyra-334 protected against cell damage in a dose-dependent manner.

Effect of porphyra-334 on ROS generation. To determine whether porphyra-334 functions as a scavenger of UVA-induced ROS generation, intracellular ROS levels were measured. As shown in Fig. 2C (upper panel), the level of ROS in UVA-irradiated cells increased compared with non-irradiated cells. UVA-exposed cells showed a significant reduction in DCF-DA staining in the presence of porphyra-334, indicating that porphyra-334 inhibited the intracellular accumulation of ROS in human skin fibroblasts damaged by UVA-induced oxidant stress.

Effect of porphyra-334 on SA- $\beta$-gal activity. SA- $\beta$-gal staining was performed to observe SA- $\beta$-gal activity, which is a biomarker of senescence. Images clearly indicated that the cells were induced to a senescence-like state by UVA 

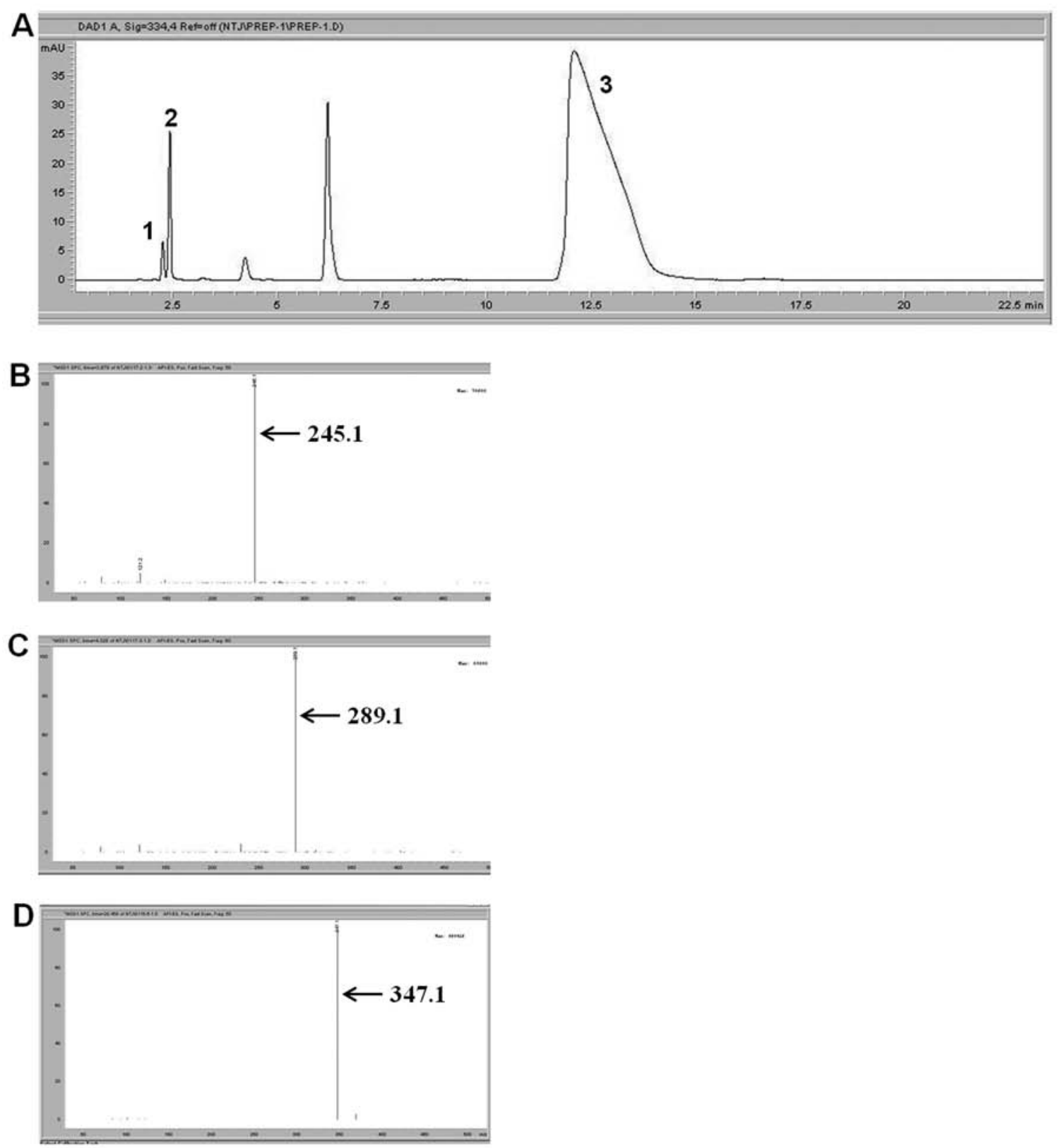

Figure 1. Chromatographic separation of mycosporine-like amino acids (MAAs) from Porphyra (P.) yezoensis. (A) High-performance liquid chromatography (HPLC) chromatogram of P. yezoensis, showing the peaks for peak 1 (2.29 min), peak 2 (2.493 min) and peak 3 (11.53 min). Mass spectrometry (MS) spectra and chemical structures of peaks 1, 2 and 3 exhibits [M+H $]^{+}$ions at $m / z$ (B) 245.1 , (C) 289.1 and (D) 347.1 .

irradiation. The inhibitory activity of porphyra-334 was also observed and found to effectively suppress the expression of SA- $\beta$-gal in a dose-dependent manner (Fig. $2 \mathrm{C}$ lower panel).

Effect of porphyra-334 on MMP expression. To determine whether porphyra-334 inhibited MMP expression induced by UVA irradiation, human skin fibroblasts were irradiated with UVA $\left(10 \mathrm{~J} / \mathrm{cm}^{2}\right)$ and treated with porphyra-334 for $24 \mathrm{~h}$. Based on RT-PCR, UVA irradiation significantly increased MMP-1 mRNA expression in culture medium (Fig. 3A). To investigate the dose-dependent effect of porphyra-334, the cells were treated with different concentrations of porphyra-334 ranging from 10 to $40 \mu \mathrm{M}$. The highest concentration of porphyra-334 inhibited MMP-1 mRNA expression in UVA irradiated human skin fibroblasts up to $56.2 \%$, and the inhibition was dose-dependent. The inhibition of MMP-8 was similar to MMP-1, but not MMP-13. MMP-13 expression in the presence of porphyra-334 was similar to the UVA-irradiation control. Porphyra-334 reduced the elevated MMP expression, with the exception of MMP-13, at the gene and protein levels compared with the control groups, which were irradiated without treatment. Of the three MMPs, MMP-1 was the most active compared with the positive control. Thus, porphyra-334 exerted a protective effect on UVA-induced collagen degradation via the negative regulation of MMP expression.

Effect of porphyra-334 on UVA-induced intracellular procollagen. To evaluate the effect of porphyra-334 on collagen synthesis, human skin fibroblasts were treated 
A

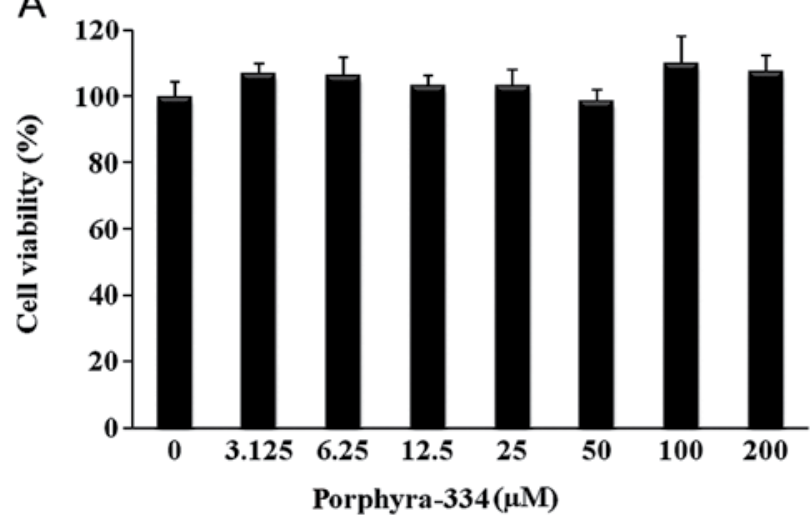

B

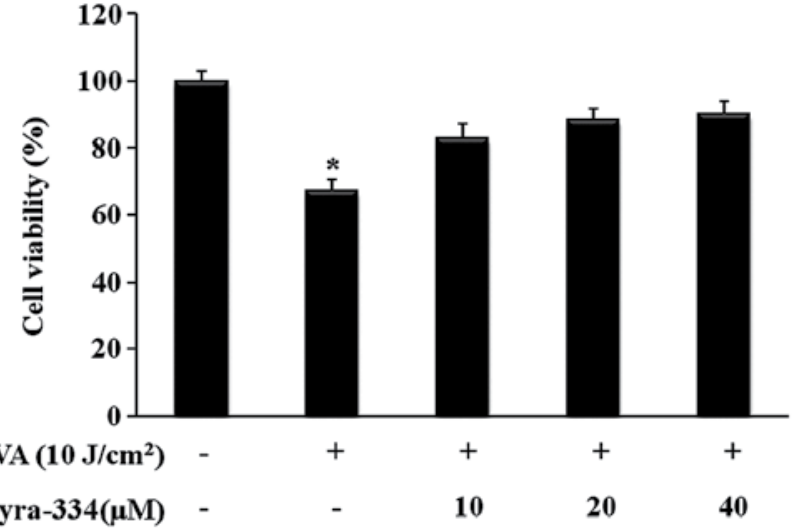

\section{C}
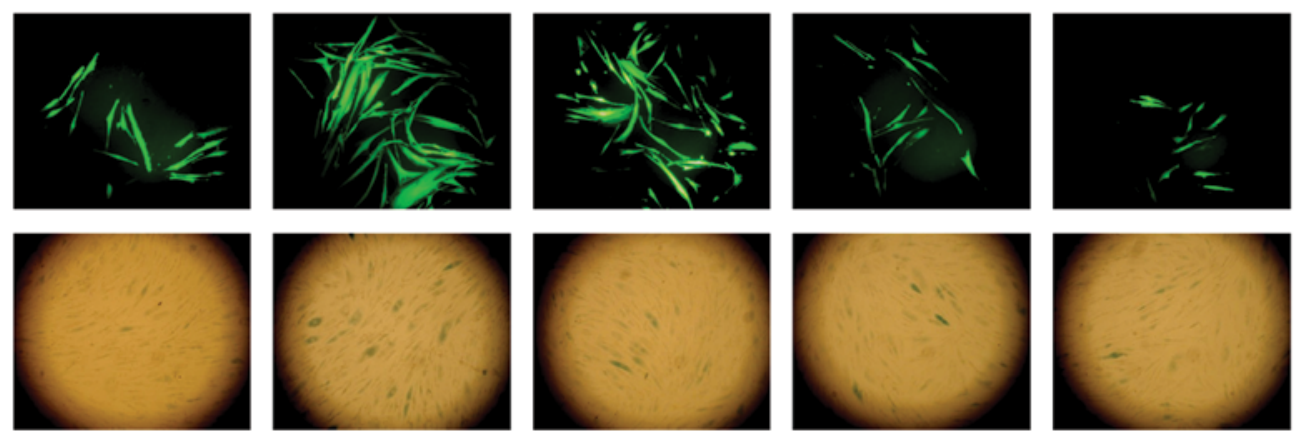

UVA $\left(10 \mathrm{~J} / \mathrm{cm}^{2}\right)$

Porphyra-334( $\mu \mathrm{M})$

)

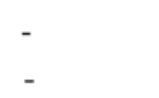

10
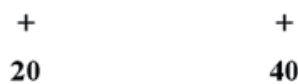

40

Figure 2. Effect of porphyra-334 on UVA-induced cell viability, reactive oxygen species (ROS) generation and senescence-associated $\beta$-galactosidase (SA- $\beta$-gal) expression in human skin fibroblasts. (A) Porphyra-334 (0-200 $\mu \mathrm{M})$ did not exert cytotoxic effects on the proliferation of fibroblasts. (B) Cells were exposed to UVA $\left(10 \mathrm{~J} / \mathrm{cm}^{2}\right)$ irradiation, and cell viability (\%) was determined. (C) Porphyra-334 treatment inhibited the production of intracellular ROS and the activity of SA- $\beta$-gal in a dose-dependent manner. ${ }^{*} \mathrm{P}<0.05$ compared with the only non-UVA irradiated group.

A

\begin{tabular}{|c|c|c|c|c|}
\hline \multicolumn{5}{|c|}{ CCD-986sk } \\
\hline UVA $\left(10 \mathrm{~J} / \mathrm{cm}^{2}\right)$ & $-\quad+$ & + & + & + \\
\hline Porphyra-334 $(\mu \mathrm{M})$ & - & 10 & 20 & 40 \\
\hline MMP-1 & - & - & & 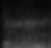 \\
\hline MMP-8 & - & - & - & - \\
\hline MMP-13 & - & $=$ & - & - \\
\hline GAPDH & - & - & - & - \\
\hline
\end{tabular}

B

\begin{tabular}{|c|c|c|c|c|}
\hline \multicolumn{5}{|c|}{ CCD-986sk } \\
\hline UVA $\left(10 \mathrm{~J} / \mathrm{cm}^{2}\right)$ & + & + & + & + \\
\hline Porphyra-334 $(\mu \mathrm{M})$ & - & 10 & 20 & 40 \\
\hline MMP-1 & wens & $\cos$ & $=$ & ms: \\
\hline MMP-8 & & & & \\
\hline MMP-13 & 66 & ex. & ats & \\
\hline GAPDH & & & & \\
\hline
\end{tabular}

Figure 3. Effect of porphyra-334 on UVA-induced production of matrix metalloproteinases (MMPs) in human skin fibroblasts. Following UVA irradiation at $10 \mathrm{~J} / \mathrm{cm}^{2}$, cells were treated with 10,20 and $40 \mu \mathrm{M}$ porphyra-334 for $24 \mathrm{~h}$, and MMP expression levels were measured by reverse transcription-polymerase chain reaction (RT-PCR) and western blot analysis. (A) RT-PCR results revealed an association between porphyra-334 concentrations and MMP mRNA expression. mRNA expression was normalized to the housekeeping gene, GAPDH. (B) Western blot analysis revealed that porphyra-334 prevented the UVA-induced expression of MMPs. GAPDH was the loading control for western blot analysis.

with various concentrations of porphyra-334 $(0-40 \mu \mathrm{M})$ for $>24 \mathrm{~h}$. The secreted procollagen level was measured in the culture medium using an ELISA assay, as described in the 'Materials and methods'. As shown in Fig. 4A, the collagen content was $319.5 \pm 0.069 \mathrm{ng} / \mathrm{ml}$ in the non-irradiated cells but
$217.333 \pm 0.177 \mathrm{ng} / \mathrm{ml}$ in the UVA-irradiated cells. Procollagen secretion levels increased by $269.167 \pm 9.090,253.833 \pm 1.464$ and $271.833 \pm 7.224 \mathrm{ng} / \mathrm{ml}$ in the presence of porphyra-334 at concentrations of 10,20 and $40 \mu \mathrm{M}$, respectively. Thus, porphyra-334 has a protective effect on collagen degradation 
A

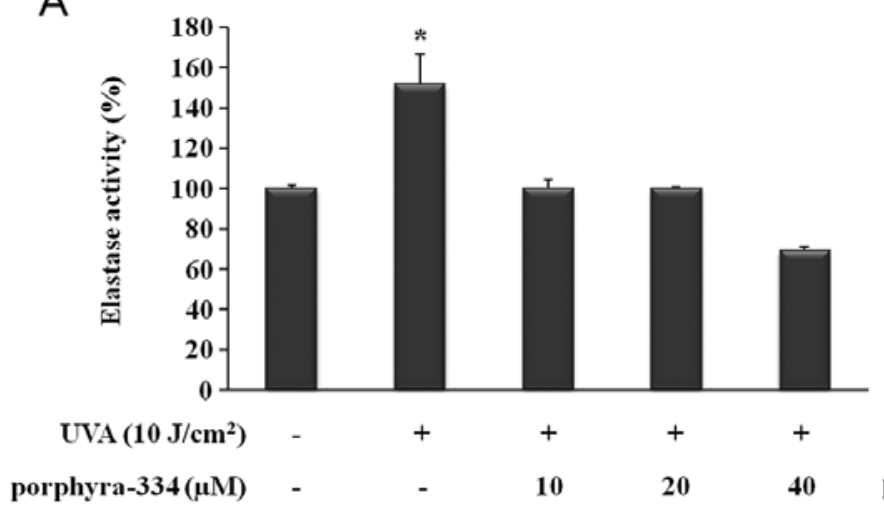

B

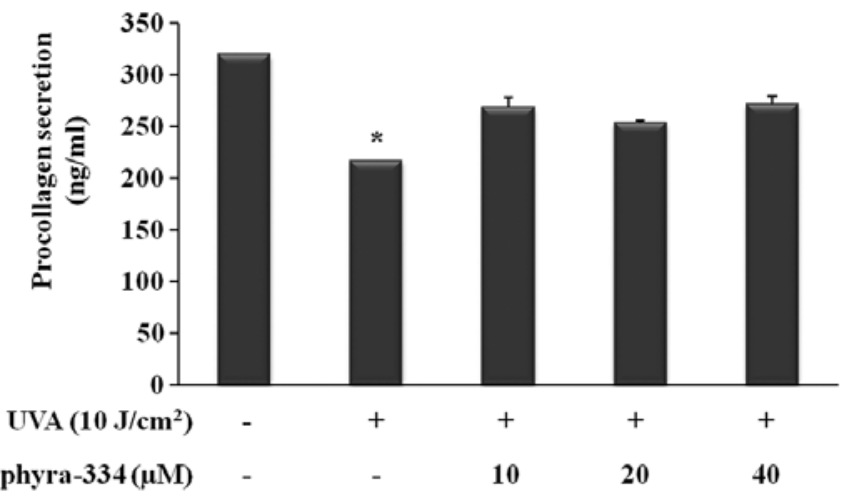

C

\begin{tabular}{|c|c|c|c|c|c|}
\hline \multicolumn{6}{|c|}{ CCD-986sk } \\
\hline UVA $\left(10 \mathrm{~J} / \mathrm{cm}^{2}\right)$ & - & + & + & + & + \\
\hline porphyra-334 ( $\mu \mathrm{M})$ & - & - & 10 & 20 & 40 \\
\hline Elastin & $\infty$ & $=$ & $\Rightarrow$ & $\infty$ & 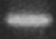 \\
\hline COL1A & 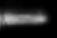 & $=$ & $=$ & - & 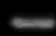 \\
\hline GAPDH & - & 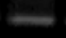 & $=$ & $=$ & - \\
\hline
\end{tabular}

D

\begin{tabular}{|c|c|c|c|c|c|}
\hline \multicolumn{6}{|c|}{ CCD-986sk } \\
\hline UVA $\left(10 \mathrm{~J} / \mathrm{cm}^{2}\right)$ & - & + & + & + & + \\
\hline porphyra-334 $(\mu \mathrm{M})$ & - & - & 10 & 20 & 40 \\
\hline Elastin & $=$ & $\rightarrow$ & $m$ & ater & $m$ \\
\hline COL1A & & & 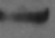 & 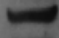 & 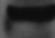 \\
\hline GAPDH & & & & & 5 \\
\hline
\end{tabular}

Figure 4. Effect of porphyra-334 on the UVA-induced degradation of elastin and collagen in human skin fibroblasts. Following UVA irradiation at $10 \mathrm{~J} / \mathrm{cm}^{2}$, the cells were treated with 10,20 and $40 \mu \mathrm{M}$ of porphyra-334 for $24 \mathrm{~h}$. (A) The procollagen levels and (B) elastase activity was measured by ELISA. (C) The mRNA transcription and (D) protein level of type I collagen and elastin expression levels were measured by reverse transcription-polymerase chain reaction (RT-PCR) and western blot analysis. "P<0.05 compared with the only non-UVA irradiated group.

by enhancing collagen synthesis in photodamaged human skin fibroblasts.

Effect of porphyra-334 on UVA-induced elastase activity. UV irradiation is known to cause elastin degradation by activating elastase (18), and loss of skin elastin caused by UVA irradiation results in wrinkle formation. In this study, the elastase activity of human skin fibroblasts in response to porphyra-334 was confirmed based on the release of p-nitroaniline. As shown in Fig. 4B, elastase activity increased by $51.9 \%$ in the supernatant and intracellular contents, respectively, following UVA irradiation compared with the non-irradiated cells. This increase in the elastase inhibitory effect was decreased by porphyra-334 treatment at 10,20 and $40 \mu \mathrm{M}$ after UVA irradiation by $51.9,51.9$ and $82.5 \%$ compared with the UVA-irradiated cells, respectively.

Effect of porphyra-334 on UVA-induced collagen and elastin degradation. To examine the effect of porphyra-334 on collagen and elastin degradation, human skin fibroblasts previously stimulated with UVA irradiation were incubated with various concentrations of porphyra-334 (0-40 $\mu \mathrm{M})$. The expression of the specific elastin and type I collagen at the mRNA and protein levels was determined by RT-PCR and western blot analysis, respectively. The mRNA and protein levels of type I collagen and elastin are shown in Fig. 4C and D. Expression of type I collagen was decreased in UVA-irradiated cells, while the decrease in cellular collagen levels following UVA exposure was prevented in a dose-dependent manner in the presence of porphyra-334. Similarly, the expression of elastin was enhanced following porphyra-334 treatment after UVA irradiation. Results of the western blot analysis were in concordance with those of RT-PCR. These results indicated that porphyra-334 may be involved in collagen synthesis by regulating collagen-degrading MMP expression and elastinase activity.

\section{Discussion}

Porphyra sp. has been used to protect against a variety of diseases. However, the intracellular signaling and protective effects of porphyra-334 against UVA-induced photodamage in human skin fibroblasts remains poorly understood. Numerous studies (19-21) have explored the impact of UV irradiation on skin cells, but the beneficial effect of photoprotective agents on UVA-induced damage in human skin is not well characterized. UVA is a potent inducer of various ROS, and it causes lipid peroxidation in cell membranes. Antioxidant defense mechanisms may be overwhelmed by excessive free radical generation, which damages the cells and increases the chances of photocarcinogenesis. Development of novel antioxidant strategies to supplement the natural defense mechanism of the skin may be an important strategy to reduce UV-induced effects. This study showed that porphyra-334, a rich source of MAA derived from $P$. yezoensis, is capable of reducing the adverse effects of UVA-mediated cutaneous damage.

Photoaging associated with UV irradiation is thought to play a central role in initiating and driving the signaling events that 
lead to cell responses. UV radiation of skin decreases antioxidant enzyme concentrations (22) and increases hydrogen peroxides and other ROS $(23,24)$. UV irradiation initiates the generation of ROS and alters gene and protein structure and function, leading to skin damage. Porphyra-334 was shown to dose-dependently decrease intracellular UVA-induced ROS generation in human skin fibroblasts based on a modified DCF-DA fluorescence assay. Since the generation of MMPs is significantly induced by ROS (25), we showed that the ROS scavenging of porphyra-334 was comparable to the non-UV irradiated control. This suggests that porphyra-334 controls the expression of MMPs by scavenging excess ROS in damaged skin fibroblasts.

UV irradiation enhances the decomposition of skin connective tissue by activating MMPs responsible for the degradation of skin collagen and inhibiting collagen synthesis of ECM in connective tissues (26). In this study, we observed the upregulation of MMPs (especially MMP-1) and the degradation of dermal collagen following UV irradiation. Porphyra-334 was a potent suppressor of UVA-induced MMP generation, and it also inhibited the MMP-1-initiated degradation of type I collagen. Therefore, inhibition of collagenase MMP expression or activation of collagen synthesis may be an effective strategy to prevent wrinkle formation following UVA irradiation. This mechanism predicts that a free radical scavenger may prevent UV-induced dermal damage by inhibiting MMP induction. These findings suggest that the regulation of MMPs and type I collagen levels in UV-irradiated fibroblasts may be related to the inhibition of ROS generation by porphyra-334. MAAs from red algae are known to effectively decrease MMPs and increase type I collagen expression levels to prevent premature skin aging (27). Results of this study suggest that porphyra-334 increases procollagen production by suppressing MMP gene expression and reducing MMP production, which can reduce cytokine secretion by human skin fibroblasts. Many algae have been screened for potential MMP inhibitors. For example, Corallina pilulifera (28), Ecklonia cava (29), Laurencia undulata (30) and Amphiroa dilatata (31) exhibited inhibitory effects on MMP activities. In this study, porphyra-334 was safe to human skin fibroblasts and significantly decreased the expression of MMPs induced by UVA irradiation.

Wrinkle formation in the skin is closely associated with the degradation of ECM, and UV irradiation is known to induce the degradation of ECM (32). UV irradiation enhances collagenase activity and contributes to wrinkle formation through the degradation of collagen in the dermal ECM $(33,34)$. Therefore, collagenase inhibitors have been identified as potential therapeutic agents that protect against photoaging and wrinkle formation (35). Collagen is the main component of the ECM of dermal connective tissue, and its concentration decreases with photoaging. Once collagen is initially cleaved by MMP-1, MMP-13 and other MMPs, collagen breakdown is further promoted. The enzyme mainly responsible for collagen breakdown in skin is MMP-1, which cleaves types I, III, VII, VIII and X collagen. As reported previously with increasing photoaging, MMP-1 levels increase and collagen synthesis decreases in sun-protected human skin in vivo (36). In this study, the exposure of human skin fibroblasts to UVA significantly decreased type I collagen levels and increased MMP secretion, both of which were reversed by porphyra-334. Elastin is important in the dermis (37), and
UV exposure has been shown to cause elastin degradation by activating elastase (38). As shown in Fig. 4B, the inhibitory effect of porphyra-334 on elastase activity was significant at a concentration of $\geq 10 \mu \mathrm{M}$.

Overall, porphyra-334 of $P$. yezoensis significantly inhibits ROS production, reduces MMP expression, and induces type I collagen, elastin at the mRNA and protein levels in a dose-dependent manner. These data suggest that porphyra-334 is a potential candidate for the prevention and treatment of skin photoaging. Additionally, porphyra-334 can be used to characterize the signal transduction pathways and molecular mechanisms involved in the anti-photoaging process.

\section{Acknowledgements}

This study was supported by the Basic Science Research Program through the National Research Foundation of Korea (NRF) funded by the Ministry of Education (2012R1A6A1028677).

\section{References}

1. Ichihashi M, Ueda M, Budiyanto A, et al: UV-induced skin damage. Toxicology 189: 21-39, 2003.

2. Jaiswal AK: Nrf2 signaling in coordinated activation of antioxidant gene expression. Free Radic Biol Med 36: 1199-1207, 2004.

3. Marchioli R, Schweiger G, Tavazzi L and Valagussa F: Antioxidant vitamins and prevention of cardiovascular disease: epidemiological and clinical trial data. Lipids 36: S53-S63, 2001.

4. Chin YW, Balunase MJ, Chai HB and Kinghorn AD: Drug discovery from natural sources. AAPS J 8: E239-E253, 2006.

5. Cho S, Lee MJ, Kim MS, et al: Infrared plus visible light and heat from natural sunlight participate in the expression of MMPs and type I procollagen as well as infiltration of inflammatory cell in human skin in vivo. J Dermatol Sci 50: 123-133, 2008.

6. Gogly B, Ferré FC, Cherifi H, Naveau A and Fournier BP: Inhibition of elastin and collagen networks degradation in human skin by gingival fibroblast. In vitro, ex vivo and in vivo studies. J Cosmet Dermatol Sci Appl 1: 4-14, 2011.

7. Zhang M, Dang L, Guo F, Wang X, Zhao W and Zhao R: Coenzyme Q10 enhances dermal elastin expression, inhibits IL-1 $\alpha$ production and melanin synthesis in vitro. Int J Cosmet Sci 34: 273-279, 2012.

8. Chiang HM, Chen HC, Lin TJ, Shih IC and Wen KC: Michelia alba extract attenuates UVB-induced expression of matrix metalloproteinases via MAP kinase pathway in human dermal fibroblasts. Food Chem Toxicol 50: 4260-4269, 2012.

9. Gelse K, Pöschl E and Aigner T: Collagens-structure, function, and biosynthesis. Adv Drug Delivery Rev 55: 1531-1546, 2003.

10. Almine JF, Bax DV, Mithieux SM, et al: Elastin-based materials. Chem Soc Rev 39: 3371-3379, 2010.

11. Yuan YV and Walsh NA: Antioxidant and antiproliferative activities of extracts from a variety of edible seaweeds. Food Chem Toxicol 44: 1144-1150, 2006.

12. Andreguetti D, Stein EM, Pereira CM, Pinto E and Colepicolo P: Antioxidant properties and UV absorbance pattern of mycosporine-like amino acids analogs synthesized in an environmentally friendly manner. J Biochem Mol Toxicol 27: 305-312, 2013.

13. Piao MJ, Hyun YJ, Cho SJ, et al: An ethanol extract derived from Bonnemaisonia hamifera scavenges ultraviolet B (UVB) radiation-induced reactive oxygen species and attenuates UVB-induced cell damage in human keratinocytes. Mar Drugs 10: 2826-2845, 2012.

14. Sommaruga R, Whitehead K, Shick JM and Lobban CS: Mycosporine-like amino acids in the zooxanthella-ciliate symbiosis Maristentor dinoferus. Protist 157: 185-191, 2006.

15. Rastogi RP and Incharoensakdi A: UV radiation-induced accumulation of photoprotective compounds in the green alga Tetraspora sp. CU2551. Plant Physiol Bioch 70: 7-13, 2013.

16. Tao C, Sugawara T, Maeda S, Wang X and Hirata T: Antioxidative activities of a mycosporine-like amino acid, porphyra-334. Fish Sci 74: 1166-1172, 2008. 
17. Nakagawa K, Tsuji T, Kadoya A and Hamada T: Elastase-like enzyme activity in cultured human fibroblast. Skin Res 29: 793-797, 1987.

18. Seite S, Zucchi H, Septier D, Igondjo-Tchen S, Senni K and Godeau G: Elastin changes during chronological and photo-ageing: the important role of lysozyme. J Eur Acad Dermatol Venereol 20: 980-987, 2006.

19. Tournier C, Hess P, Yang DD, et al: Requirement of JNK for stress-induced activation of the cytochrome c-mediated death pathway. Science 288: 870-874, 2000.

20. Kulms D and Schwarz T: Molecular mechanisms involved in UV-induced apoptotic cell death. Skin Pharmacol Physiol 15: 342-347, 2002.

21. Šitum M, Buljan M, Bulat V, Lugović Mihić L, Bolanča Ž and Śimić D: The role of UV radiation in the development of basal cell carcinoma. Coll Antropol 32: 167-170, 2008.

22. Yamamoto Y: Role of active oxygen species and antioxidants in photoaging. J Dermatol Sci 27 (Suppl 1): S1-S4, 2001.

23. Masaki H, Atsumi T and Sakurai H: Detection of hydrogen peroxide and hydroxyl radicals in murine skin fibroblasts under UVB irradiation. Biochem Biophys Res Commun 206: 474-479, 1995.

24. Yasui $\mathrm{H}$ and Sakurai $\mathrm{H}$ : Chemiluminescent detection and imaging of reactive oxygen species in live mouse skin exposed to UVA. Biochem Biophys Res Commun 269: 131-136, 2000.

25. Nalson KK and Melendez JA: Mitochondrial redox control of matrix metalloproteinase. Free Radical Biol Med 37: 768-784, 2004.

26. Wlaschek M, Heinen G, Poswig A, Schwarz A, Krieg T and Scharffetter-Kochanek K: UVA-induced autocrine stimulation of fibroblast-derived collagenase/MMP-1 by interrelated loops of interleukin-1 and interleukin-6. J Photochem Photobiol 59: 550-556, 1994.

27. Pallela R, Yoon NY and Kim SK: Anti-photoaging and photoprotective compounds derived from marine organisms. Mar Drugs 8: 1189-1202, 2010.
28. Ryu B,QianZJ,Kim MM,Nam KW and Kim SK: Anti-photoaging activity and inhibition of matrix metalloproteinase (MMP) by marine red alga, Corallina pilulifera methanol extract. Radiat Phys Chem 78: 98-105, 2009.

29. Zhang C, Li Y, Shi $X$ and Kim SK: Inhibition of the expression on MMP-2, 9 and morphological changes via human fibrosarcoma cell line by 6,6'-bieckol from marine alga Ecklonia cava. BMB Rep 43: 62-68, 2010

30. Li YX, Li Y, Lee SH, Qian ZJ and Kim SK: Inhibitors of oxidation and matrix metalloproteinases, floridoside, and D-isofloridoside from marine red alga Laurencia undulata. J Agric Food Chem 58: 578-586, 2009.

31. Khan SB, Kong CS, Kim JA and Kim SK: Protective effect of Amphiroa dilatata on ROS induced oxidative damage and MMP expressions in HT1080 cells. Biotechnol Bioproc Eng 15: 191-198, 2010.

32. Rittié L and Fisher GJ: UV-light-induced signal cascades and skin aging. Ageing Res Rev 1: 705-720, 2002.

33. Uitto J: The role of elastin and collagen in cutaneous aging: intrinsic aging versus photoexposure. J Drugs Dermatol 7 : S12-S16, 2008.

34. Uitto J, Fazio MJ and Olsen DR: Molecular mechanisms of cutaneous aging: age-associated connective tissue alterations in the dermis. J Am Acad Dermatol 21: 614-622, 1989.

35. Inomata S, Matsunaga Y, Amano S, et al: Possible involvement of gelatinases in basement membrane damage and wrinkle formation in chronically ultraviolet B-exposed hairless mouse. J Invest Dermatol 120: 128-134, 2003.

36. Chung JH, Seo JY, Choi HR, et al: Modulation of skin collagen metabolism in aged and photoaged human skin in vivo. J Invest Dermatol 117: 1218-1224, 2001.

37. Labat-Robert L and Robert L: Aging of the extracellular matrix and its pathology. Exp Gerontol 23: 5-18, 1988.

38. Getie M, Schmelzer CE and Neubert RH: Characterization of peptides results from digestion of human skin elastin with elastase. Proteins 61: 649-657, 2005. 